\title{
Peruna- ja vihannesjätteen käsittely ja käyttö maatilalla
}

\author{
Marja Lehto ${ }^{1}$, Tapio Salo ${ }^{2}$, Sanna Sorvala ${ }^{1}$, Riitta Kemppainen ${ }^{3}$ ja Petri Vanhala ${ }^{3}$ \\ ${ }^{1)}$ MTT maatalousteknologian tutkimus, Vakolantie 55, 03400 Vihti, marja.lehto@mtt.fi \\ ${ }^{2)}$ MTT ympäristöntutkimus, 31600 Jokioinen, tapio.salo@mtt.fi \\ ${ }^{3)}$ MTT kasvintuotannon tutkimus, 31600 Jokioinen
}

\section{Tiivistelmä}

Peruna- ja vihannestiloilla muodostuu kasvijätettä keskimäärin 50000 tonnia vuodessa. Tämän lisäksi huomattava määrä jätettä muodostuu perunan ja juuresten kuorimotoiminnasta. Kuorimoilla kuorittavasta raaka-aineesta $30-40 \%$ joutuu jätteeksi. Peruna- ja vihanneskuorimojäte ajetaan pääosin pelloille tai käytetään eläinten rehuna. Kasvijäte tulisi käsitellä ennen peltolevitystä, esimerkiksi kompostoimalla tai mädättämällä. Käsittelemättömän kasvijätteen käyttöä rajoittavat mahdolliset jätteessä olevat kasvitaudit ja rikkakasvinsiemenet. Jätteen varastointiin tilalla tulisi kiinnittää huomiota, jottei siitä aiheutuisi päästöjä maaperään eikä pinta- ja pohjavesiin.

Tehokas tapa hyödyntää peruna- ja vihanneskuorimojätettä on sen käyttö eläinten rehuna. Peruna- ja vihannesmassa on hyvää ravintoa nautaeläimille sellaisenaan, mutta sioille se on kuumennettava. Rehukäytössä ratkaistavia asioita ovat mm. juuresmassan ja muun rehun seossuhde, jätteen säilyvyys, kuljetus ja käytetty ruokintamenetelmä. Peruna- ja vihanneskuorijätteen rehukäyttöä olisi järkevää lisätä.

Rikkakasvien siemenet leviävät mullan ja multaa sisältävien jätteiden mukana. Kompostoimattoman mullan levittäminen eri vihanneslohkolle voi edistää ongelmalajien leviämistä. On tärkeää, että joko multaa sisältävät jätteet käsitellään niin, että siemenet menettävät elinkykynsä, tai multa sijoitetaan sellaisiin kohteisiin, joissa siemenet eivät aiheuta ongelmia. Siementen elinkyvyn vähentämiseksi vihannesten mukana tullut multa olisi kompostoitava tai vanhennettava. Kompostoinnin jälkeenkin multa on turvallisempaa levittää viljakierrossa olevalle kuin vihanneskierrossa olevalle lohkolle. Riskien minimoimiseksi ulkomaista alkuperää oleva multa kannattaa sijoittaa siten, että vähäinenkään määrä rikkakasvien siemeniä ei päädy peltoon.

Vihanneksissa ja perunassa esiintyvien kasvitautien aiheuttajia ovat patogeeniset sienet, bakteerit, virukset ja ankeroiset. Parhaiten kasvitaudin aiheuttajat tuhoutuvat komposteissa tai muulla käsittelyllä, jossa lämpötila nousee riittävän korkeaksi. Riittävä hygienisoituminen kasvipatogeenien suhteen saavutetaan, kun kompostin lämpötila on useita viikkoja yli $40{ }^{\circ} \mathrm{C}$ tai viikon ajan yli $70{ }^{\circ} \mathrm{C}$. Lämpötilan lisäksi kasvitautien tuhoutumiseen vaikuttavia tekijöitä kompostissa ovat kompostin kosteus, kompostissa lisääntyvien hajottajamikrobien tuottamat toksiset yhdisteet kuten orgaaniset hapot ja ammoniakki, soluja liuottavat entsyymit ja antibiootit.

Hyvin toimivalla kompostoinnilla voidaan saada peruna- ja vihannesjätteestä käyttökelpoista maanparannusainetta. Huomiota on kiinnitettävä tuotteen raaka-aineisiin, alkuperään, käsittelymenetelmiin, tuotteen asianmukaiseen käyttöön sekä jäljitettävyyteen.

Peruna- ja vihanneskuorimon jätteet ja jätevedet -hankkeessa on tutkittu kasvijätteen osalta kuorimojätteen kompostoitumista astia-, rumpu- sekä aumakomposteissa sekä lopputuotteen laatua. Lisäksi on selvitetty kuorimojätteen rehukäyttöä, varastointia ja säilyvyyttä.

\section{Asiasanat}

vihannekset, peruna, kasvijätteet, jätteiden käsittely, kompostointi, rehu, kasvitaudit, rikkakasvit 


\section{Johdanto}

Vihannestiloilla muodostuu kasvijätettä keskimäärin 30000 tonnia vuodessa (Virtanen \& Salo 2005), lisäksi perunan varastotappio on noin 22000 tonnia vuodessa (MMM 2004). Huomattavia määriä jätettä muodostuu perunan ja juuresten kuorimotoiminnasta, jossa kuorittavasta raaka-aineesta 30-40\% joutuu jätteeksi. Kuorimoilla muodostuu kuorijätteen lisäksi multalietettä ja lajittelujätteitä. Keskikokoinen juureskuorimo kuorii n. $700000 \mathrm{~kg}$ perunaa tai juureksia vuodessa ja tästä määrästä tulee jätettä noin $300000 \mathrm{~kg}$. Juureskuorimoilta tulevan jätteen kuiva-ainepitoisuus on 5-15\%. Jäte on kuorintatavasta riippuen joko hienojakoista, märkää massaa tai lastumaista juureskuorta. Kuorimassa on huonosti säilyvää, vaikeasti kuljetettavaa ja varastoitavaa, lisäksi se vaatii kompostoinnissa runsaasti kosteutta sitovaa seosainetta.

Ympäristönsuojelulain ja -asetuksen mukaan esim. perunan tai juuresten käsittely on luvanvaraista toimintaa. Lupaharkinnassa otetaan huomioon $\mathrm{mm}$. toiminnan ympäristövaikutukset ja laitoksen sijainti. Vihannesjätteen jatkokäyttöön liittyy myös muuta lainsäädäntöä. Lannoitelakia (232/1993; HE 71/2005) sovelletaan lannoitteiden, maanparannusaineiden, lannoitettujen kasvualustojen ja kompostivalmisteiden markkinointiin, maahantuontiin ja markkinointia varten tapahtuvaan valmistukseen. Uuden rehuhygienia-asetuksen mukaan rehuaineksen valmistajan täytyy rekisteröityä ja tehdä omavalvontasuunnitelma vuoteen 2008 mennessä. Rehusta vaaditaan myös tuoteseloste. Perunan ja juuresten käsittelyssä muodostuvien orgaanisina lannoitteina käytettävien jakeiden peltolevitystä säädellään valtioneuvoston asetuksella maataloudesta peräisin olevien nitraattien vesiin pääsyn rajoittamisesta. Edellisten lisäksi perunan ja vihannesten käsittelyyn liittyvät myös mm. jätelaki ja -asetus.

\section{Rikkakasvit}

Rikkakasvien siemenet leviävät mullan ja multaa sisältävien jätteiden mukana. Sen vuoksi on tärkeää, että joko multaa sisältävät jätteet käsitellään niin, että siemenet menettävät elinkykynsä, tai vaihtoehtoisesti multa sijoitetaan sellaisiin kohteisiin, joissa siemenet eivät aiheuta ongelmia. Tehokas kompostointi, jossa koko kompostin lämpötila kohoaa pitkäksi aikaa riittävän korkeaksi, hävittää kaikki tai lähes kaikki rikkakasvien siemenet. Jos kompostiin jää kohtia, jotka eivät lämpene tarpeeksi, voi osa siemenistä selvitä hengissä.

Mullan kompostoinnin yksi tarkoitus on hävittää rikkakasvien siementen sekä kestorikkakasvien juurten ja juurakoiden elinkyky. Kompostoimattoman mullan levittäminen eri vihanneslohkolle voi edistää (vihannesten rikkakasvien) torjunta-aineita kestävien ongelmalajien leviämistä, mikä johtaa viljelykustannusten lisääntymiseen ja sadon alenemiseen. Vihanneksilla ongelmallisia rikkakasveja, joihin kemiallisella torjunnalla on huono teho, ovat ainakin pihatatar (ja muut tattaret), pelto-orvokki, matara, kylänurmikka ja sauniot. Kaalimailla ovat lisäksi ristikukkaiset rikkakasvit ja rypsi sekä savikka. Näiden lisäksi alueellisesti pahoja ovat ainakin villakko, emäkki, linnunkaali, lemmikki, hatikka ja tummarusokki (Ruuttunen 2004).

Uuden lannoitevalmistelain (HE 71/2005) asetusluonnoksessa ehdotetaan maanparannusaineeksi käytettävän mullan käsittelyyn kahden vuoden vanhentamista. Tällöin multa säilytetään kasassa ilman tukiainetta ja kasa käännetään muutaman kerran vanhentamisaikana. Mikäli multaa ei voida tai haluta kompostoida tai vanhentaa, tulee multa sijoittaa siten, ettei se aiheuta kohtuutonta riskiä. Melkein kaikenlainen multa voidaan käyttää täyttömaaksi. Kaikissa tapauksissa tulee varmistaa etteivät ongelmarikkakasvit (esim. hukkakaura) pääse kasvamaan ja leviämään pellolle. Jos multa ajetaan pellolle, on se viisainta levittää sellaisille lohkoille, joilla ei viljellä eikä edes aiota viljellä vihanneksia tai juureksia.

Kotimaista alkuperää olevan mullan osalta ei liene syytä jyrkkiin rajoituksiin, mutta mullan tai multaa merkittävästi sisältävän aineksen vastaanottajan tulee saada riittävästi tietoa mullan alkuperästä ja rikkakasvinsiemeniin vaikuttavista käsittelyistä. Pellolle levitettäessä paras sijoituspaikka olisi sama lohko miltä multa on peräisin. Tällöin mullan mukana ei tule lohkolle uusia rikkakasvilajeja. Ulkomaista alkuperää olevan mullan käsittelyssä ja levittämisessä on noudatettava harkintaa ja varovaisuutta, ei ainoastaan rikkakasvien leviämisen vaan myös kasvitautien ja tuhoeläinten, mm. ankeroisten, leviämisen estämiseksi. 


\section{Kasvitaudit}

Kasvitauteja aiheuttavien mikrobien tuhoutumiseen kompostissa vaikuttavat monet osatekijät, mutta suurin yksittäinen vaikutus on kuitenkin sillä, miten korkeaksi kompostin lämpötila nousee ja kuinka kauan lämpötila pysyy korkealla. Kompostin termofiilisen vaiheen korkea lämpötila, yli $70{ }^{\circ} \mathrm{C}$, tuhoaa taudinaiheuttajien kasvusolut helposti. Riittävä hygienisoituminen kasvipatogeenien suhteen saavutetaan, kun kompostin lämpötila on useita viikkoja yli $40{ }^{\circ} \mathrm{C}$ tai viikon ajan yli $70{ }^{\circ} \mathrm{C}$ (Hoitink \& Poole 1980). Osa tauteja aiheuttavista sienistä ja bakteereista muodostaa kestoitiöitä, joiden ansiosta ne voivat säilyä lisääntymiskykyisinä sellaisissakin olosuhteissa, jotka poikkeavat selvästi optimiolosuhteista.

Kirjallisuudesta löytyy useita erilaisia raja-arvoja patogeenien tuhoutumisesta kompostointiprosessissa. Kompostointiprosessi on kuitenkin riippuvainen kompostointimenetelmästä, kompostoitavasta materiaalista ja hyvin monista muista tekijöistä, jotka vaikuttavat siihen, miten kompostoituminen etenee. Kompostissa letaalilämpötilat ovat selvästi alhaisemmat kuin laboratorioolosuhteissa.

\section{Kompostointi}

Kompostointi on biologinen prosessi, jossa monilajinen aerobinen mikrobikanta hajottaa orgaanista ainetta kosteissa, aerobisissa ja riittävän lämpimissä olosuhteissa. Hajotusprosessi kestää materiaalista ja olosuhteista riippuen viikkoja, jopa kuukausia. Hajotusprosessi tuottaa runsaasti energiaa siten, että aktiivisimman hajotusvaiheen aikana kompostin lämpötila nousee yleensä yli $50{ }^{\circ} \mathrm{C}$, jopa $70{ }^{\circ} \mathrm{C}$ :een. Lopputuotteena syntyy stabiilia humusainetta eli kompostimultaa, vettä, hiilidioksidia ja epäorgaanisia suoloja. Taulukossa 1. on esitetty arvoja kompostoinnin optimiolosuhteille.

Taulukko 1. Optimiolosuhteet kompostoinnissa.

\begin{tabular}{|l|l|}
\hline $\mathrm{pH}$ & $6-8$ \\
\hline Kosteus & $40-60 \%$ \\
\hline $\mathrm{C}: \mathrm{N}$ & $25-35$ \\
\hline happi & $>5 \%$ \\
\hline
\end{tabular}

\section{Rehukäyttö}

Peruna- ja vihanneskuorijätteen käytöllä karjan rehuna on monia etuja. Se säästää luonnonvaroja, lisää paikallisten tuotteiden käyttöä ja ylläpitää ravinteiden kiertoa (Wlcek \& Zollitsch 2004). Kuorimassan arvo karjanomistajalle riippuu $\mathrm{mm}$. kuljetusmatkasta, varastoinnista ja kuiva-ainepitoisuudesta (Bradshaw 2002). Peruna- ja vihanneskuorimassan kosteuspitoisuus on yli $80 \%$, joten sekoitettaessa sitä muuhun rehuun, on tärkeää huolehtia eläinten riittävästä kuiva-aineen saannista. Jos kuiva-aine pitoisuutta ei ole kontrolloitu, voi karjalle aiheutua aksidioosia (Murphy 1997). Kuorimolta tulevan kuorimassan määrä, kuiva-ainepitoisuus ja koostumus voivat vaihdella päivittäin (Boyles 2004). Karja täytyy ensin totuttaa peruna- ja vihanneskuorimassaan. Käytettäessä kuorimassaa eläinten ruokinnan osana, on hyödyllistä eläinten kannalta, pitää kuorimassan ja rehun suhde vakiona (Bradshaw ym. 2002).

Peruna- ja vihanneskuorimassa soveltuu liemiruokintalaitteisiin ja apevaunuruokintaan. Liha- ja maitokarjalle perunakuorimassan voi antaa sellaisenaan, mutta sioille perunakuorimassa on hyvä kuumentaa, koska siat eivät sulata tärkkelyspitoista ravintoa raakana (Valaja 2004). Perunakuorimassan on todettu parantavan rehun maistuvuutta, kun sitä sekoitetaan muuhun rehuun (Anderson \& Schatz 2003). Rehuksi käytettävään kuorimassaan tulee käyttää pestyjä, puhtaita raakaaineita.

\section{Aineisto ja menetelmät Porkkanajätteen kompostointi laboratoriossa}

Porkkanankuorijätettä, johon oli sekoitettu turvetta, olkea, haketta sekä kananlantaa kompostoitiin MTT/Vakolan säähuoneessa, jonka lämpötila oli $20{ }^{\circ} \mathrm{C}$ ja kosteus $70 \%$. Seosta kompostoitiin lieriöissä, joiden pohjissa oli verkko, jonka läpi ilma pääsi kulkemaan, kuva 1. Seosta käännettiin aluksi kerran viikossa ja myöhemmin kahden viikon välein. 


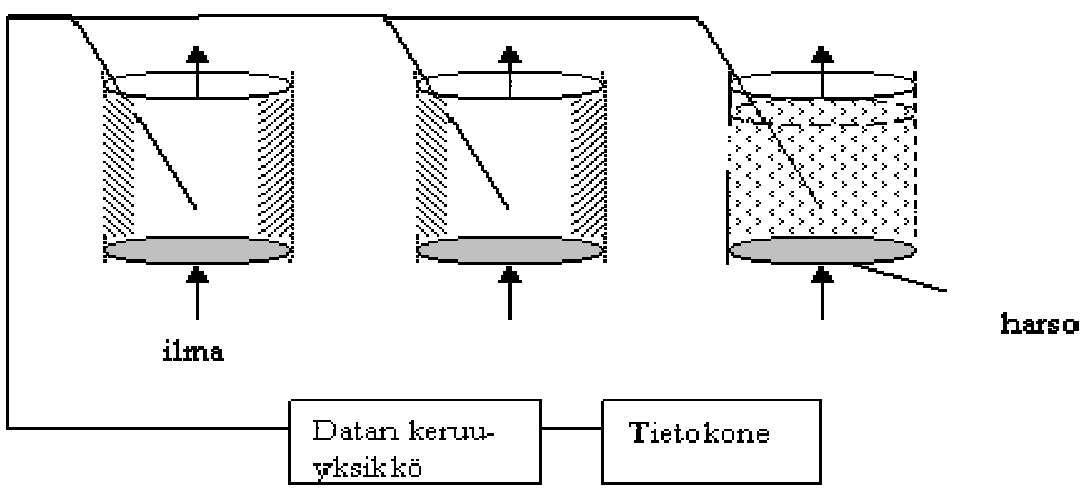

Kuva 1. Kompostointikokeessa käytetty koejärjestely.

Lähtöaineista tehtiin neljä erilaista seosta ja kaikista tehtiin neljä rinnakkaisnäytettä. Taulukossa 2. ovat seosaineet ja niiden tilavuudet litroina (1). Lämpötilaa seurattiin 3 kk:n ajan. Alku- ja lopputuotteista määritettiin kuiva-aine, hiili- ja typpi-, nitraatti- ja ammoniumpitoisuudet, $\mathrm{pH}$, tilavuus, johtokyky ja johtoluku. Lisäksi jokaiseen kompostointiastiaan lisättiin näyte, jossa oli möhöjuurta aiheuttavan kasvipatogeenin (Plasmodiophora brassicae) muodostamia äkämiä sekä möhöjuuren saastuttamaa maata. Kompostoinnin päätyttyä möhöjuurinäytteille tehtiin kasvihuoneessa biotesti (Bruns ym. 1994), jonka avulla selvitettiin, oliko kompostointi pystynyt tuhoamaan kasvipatogeenin. Lähtöaineiden ja valmiiden kompostien rikkakasvinsiemenpitoisuus määritettiin idättämällä.

Taulukko 2. Kompostien seossuhteet.

\begin{tabular}{|l|l|l|l|l|l|l|}
\hline komposti & porkkana (l) & olki (l) & turve (l) & hake (l) & kananlanta (l) & yhteensä (l) \\
\hline 1 & 25 & 12 & 20 & 8 & 0 & 65 \\
\hline 2 & 23 & 0 & 25 & 9 & 0 & 57 \\
\hline 3 & 23 & 12 & 20 & 10 & 10 & 74 \\
\hline 4 & 30 & 0 & 28 & 15 & 10 & 82 \\
\hline
\end{tabular}

\section{Porkkana- ja perunankuorimojätteen rumpukompostointi}

Porkkana- ja perunakuorimolta tulevaa jätettä kompostointiin $5 \mathrm{~m}^{3}:$ n rumpukompostorissa kahdessa eri seossuhteessa, kuva 2. Porkkanaa sekoitettiin sipulinkuorien, turpeen ja hakkeen kanssa seossuhteissa 40:10:30:20 ja 30:10:40:20 tuoretilavuutta. Perunajätettä, turvetta ja haketta sekoitettiin seossuhteissa 35:45:20 ja 42:42:20. Kokeen alussa rumpuun lisättiin seosta siten, että massan tilavuus oli $3,5 \mathrm{~m}^{3}$. Tämän jälkeen rumpuun lisättiin viitenä päivänä viikossa $0,5-1 \mathrm{~m}^{3}$ juuresseosta ja samalla rummun toisesta päästä poistettiin $0,4-0,7 \mathrm{~m}^{3}$. Seoksen viipymäaika rummussa oli 7 vuorokautta. Porkkanajätteen kompostoinnissa rumpu pyörähti kaksi kertaa vuorokaudessa ja perunajätteellä neljä kertaa vuorokaudessa.

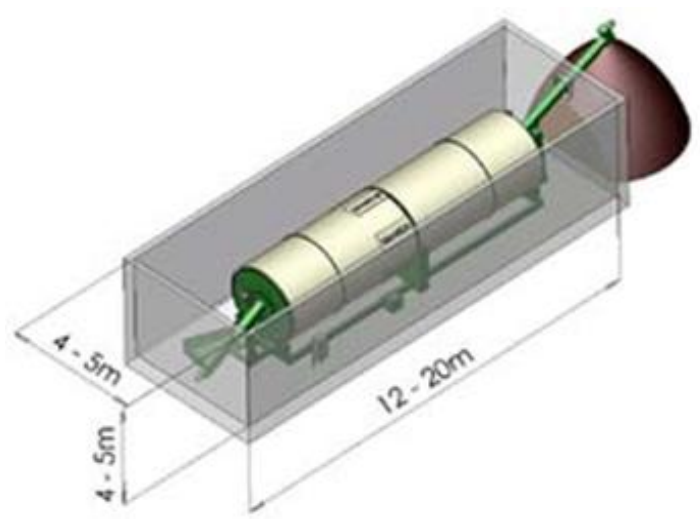

Kuva 2. Rumpukompostori, 25-125 $\mathrm{m}^{3}$. Hankkeessa käytetyn rummun tilavuus oli $5 \mathrm{~m}^{3}$. 


\section{Rehukäyttö}

Lantun ja porkkanan kuorijätteestä otettiin näytteet ja näistä määritettiin rehun laatua kuvaavia tekijöitä, kuten kuiva-aine, raakavalkuainen, raakakuitu, raakarasva, typettömät uuteaineet ja tuhka sekä orgaanisen aineen sulavuus, joka määritettiin in vitro pepsiini-sellulaasiliukoisuutena. Orgaanisen aineen sulavuus (tarkemmin orgaanisen aineen pepsiini-sellulaasisulavuus) on in vitro menetelmä jossa käytetään kaupallista sellulaasientsyymiä. Menetelmä kuvaa märehtijällä tapahtuvaa pötsisulatusta, joka tapahtuu pötsimikrobien tuottamien sellulaasientsyymien avulla. Se ei ole täysin sama asia, kuin eläimessä tapahtuva sulatus, mutta se on paras laboratoriomenetelmä. Analyysituloksista laskettiin rehutaulukon sulavuuskertoimilla ja väkirehukaavalla rehuyksikköarvot (RY-arvot), taulukko 6. (MTT 2004).

\section{Perunankuorimojätteen säilyvyyskokeet}

Kuorimojätteen tai sivutuotteen rehukäyttöä rajoittaa sen huono säilyvyys ja kuljetus tilalta toiselle. Jotta kuljetuksia voitaisiin vähentää, pitäisi kuorimassan säilyvyyttä parantaa. Perunankuorijätteelle tehtiin säilyvyyskoe. Koe tehtiin lisäämällä $5 \mathrm{~kg}$ perunakuorimassamäärään $25 \mathrm{ml}$ säilöntäainetta $(5$ $\mathrm{ml} / \mathrm{kg}$ perunamassaa). Säilöntäaineina olivat AIV 2+ (muurahaishappoa 76\%, ammoniumformiaattia $5,5 \%$ ) ja AIV 2000 (muurahaishappoa 55\%, ammoniumformiaattia $24 \%$, propionihappoa $5 \%$, bentsoehappoa $1 \%$, etyylibentsoaattia $1 \%$ ). Lisäksi oli mukana 0 -käsittely, jossa perunarehua säilöttiin ilman lisäaineita. Rehua säilytettiin noin $50 \mathrm{~cm}$ korkeassa lieriössä 2 viikkoa. Tänä aikana otettiin näytteitä 1 viikon kuluttua aloituksesta ja kokeen päättyessä. Lieriöt olivat noin 20 asteen lämpötilassa.

\section{Tulokset ja tulosten tarkastelu}

\section{Porkkanajätteen kompostointi laboratoriossa}

Kaikkien kompostien lämpötilat nousivat 2-3 vuorokauden kuluessa kompostoinnin aloittamisesta keskimäärin $40^{\circ} \mathrm{C}$ :een, maksimilämpötilan ollessa $47^{\circ} \mathrm{C}$. Kompostien lämpötilat pysyivät korkealla 67 vrk, minkä jälkeen ne laskivat hitaasti 20-30 ${ }^{\circ} \mathrm{C}$ :een. Kuukauden kuluttua kompostoinnin aloittamisesta kaikkien kompostien lämpötilat olivat pudonneet lähelle huonelämpötilaa ja kompostit olivat jo multamaisia. Biotestien tulokset osoittivat, että suurin osa komposteista oli hygienisoitunut siinä määrin, että möhöjuurta aiheuttava sieni oli tuhoutunut. 16 näytteestä vain kahdessa patogeenin infektoimiskyky oli säilynyt lievänä. Kompostien lähtöaineissa ei ollut itäviä rikkakasvien siemeniä, ainoastaan oljessa oli muutamia ohran siemeniä, joiden itävyys tuhoutui kompostoinnissa.

Taulukko 3. Kompostista mitattuja pitoisuuksia kokeen päättyessä.

\begin{tabular}{|c|c|c|c|c|c|c|c|c|c|}
\hline & Kuiva-aine & Tot-C & Tot-N & $\mathbf{C} / \mathbf{N}$ & $\mathbf{N H}_{4}-\mathbf{N}$ & $\mathbf{N O}_{3}-\mathbf{N}$ & $\mathbf{p H}$ & Johtokyky & $\begin{array}{c}\text { Kuiva-aineen } \\
\text { tilavuuspaino }\end{array}$ \\
\hline & $\%$ & $\%$ & $\%$ & & $\mathrm{mg} / \mathrm{kg}$ & $\mathrm{mg} / \mathrm{kg}$ & & $\mathrm{mS} / \mathrm{m}$ & $\mathrm{kg} / \mathrm{dm}^{3}$ \\
\hline 1 & 31,2 & 44,4 & 1,1 & 41 & 197 & 1757 & 6,9 & 115 & 0,20 \\
\hline 2 & 27,5 & 43,4 & 1,0 & 45 & 175 & 1248 & 6,7 & 74 & 0,19 \\
\hline 3 & 33,6 & 38,9 & 1,6 & 25 & 355 & 3278 & 7,5 & 289 & 0,26 \\
\hline 4 & 31,7 & 38,6 & 1,4 & 28 & 182 & 2750 & 7,8 & 249 & 0,25 \\
\hline
\end{tabular}

Kompostien kuiva-ainepitoisuudet olivat kompostoinnin alussa $25-30 \%$ ja lopussa $28-34 \%$. Kananlantaa sisältäneet kompostit olivat typpipitoisempia ja johtokyvyltään korkeampia. Kananlannan typpi paransi myös kompostien 3 ja 4 hiili-typpi -suhdetta. Kolmen kuukauden kompostoinnin jälkeen typpi oli pääosin nitraattimuodossa, mikä on tyypillistä valmiille kompostille. Verrattaessa $\mathrm{C} / \mathrm{N}$ suhteita kompostoinnin lopussa ja alussa olivat kompostit 3 ja 4, komposteihin 1 ja 2 verrattuna, pidemmälle kompostuneita, taulukko 3. 


\section{Rumpukompostointi}

Porkkana- ja perunakuorimoiden kuorijätekomposteista mitatut kuiva-aineen ja orgaaninen kuivaaineen pitoisuudet sekä $\mathrm{pH}$ kahdella eri seossuhteella alku- ja lopputuotteista on esitetty taulukoissa 4 ja 5. Kuiva-ainepitoisuus eri seoksilla oli porkkanalla n. $20 \%$ ja perunalla n. $30 \%$. Seosaineita oli lisätty suhteellisen runsaasti.

Taulukko 4. Porkkanankuorikompostin lähtö- ja lopputuotteen mittaustuloksia.

\begin{tabular}{|l|l|l|l|}
\hline Seossuhde porkkana:sipuli:turve:hake & kuiva-aine \% & VS \% & pH \\
\hline 40:10:30:20 alussa & 19 & 94 & 4,0 \\
\hline rumpukompostointivaiheen lopussa & 20 & 89 & 5,6 \\
\hline 30:10:40:20 alussa & 21 & 96 & 4,0 \\
\hline rumpukompostointivaiheen lopussa & 19 & 92 & 5,6 \\
\hline
\end{tabular}

Taulukko 5. Perunankuorikompostin lähtö- ja lopputuotteen mittaustuloksia.

\begin{tabular}{|l|l|l|l|}
\hline Seossuhde peruna:turve:hake & kuiva-aine \% & VS \% & pH \\
\hline 35:45:20 alussa & 27 & 95 & 4,7 \\
\hline rumpukompostointivaiheen lopussa & 31 & 96 & 5,5 \\
\hline 42:42:20 alussa & 30 & 96 & 4,6 \\
\hline rumpukompostointivaiheen lopussa & 28 & 94 & 5,2 \\
\hline
\end{tabular}

Kaikkien seosten $\mathrm{pH}: t$ nousivat viikon rumpukompostoinnin aikana, mutta muutokset kuiva-aineen ja orgaanisen kuiva-aineen pitoisuuksissa olivat suhteellisen pieniä. Seoksen koostumus muuttui kuitenkin huomattavasti ja haju kompostoinnin jälkeen oli mieto.

Lämpötilat sekä porkkana- että perunakompostissa nousivat nopeasti yli $40 \quad{ }^{\circ} \mathrm{C}$ :een. Perunakompostissa saavutettiin korkeammat lämpötilat. Porkkanan- ja perunankuorijätteen kompostoinnissa saavutetut lämpötilat on esitetty kuvassa 3 .

Tomaatinsiementen itävyys heikkeni porkkanakompostissa vaihtelevasti, eikä itävyyden väheneminen ollut suoraan riippuvainen näytteiden viipymiseen kompostorissa. Sen sijaan perunakompostissa tomaatinsiemenet menettivät itävyytensä jo viidessä päivässä.

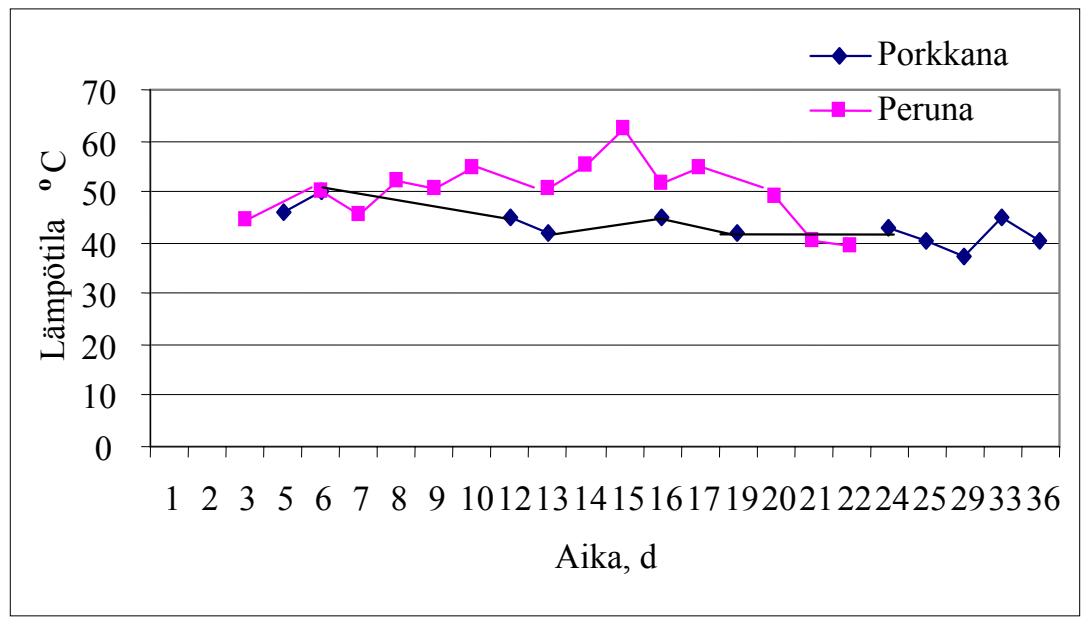

Kuva 3. Perunan- ja porkkanankuorikompostin lämpötiloja kompostirummussa.

\section{Rehukäyttö}

Lantun- ja porkkanankuoren RY-arvot ovat jonkin verran alempia kuin rehutaulukon koko juurikkaan arvot, taulukko 6. Porkkana ja lanttu soveltuvat hyvin märehtijöiden rehuksi, joko kuorimassana tai kokonaisina, ja niiden sulavuus on korkea. Porkkanan ja lantun käyttöä märehtijöiden rehuna rajoittaa 
enemmänkin rehun säilyvyys ja hygieeninen laatu sekä ruokintateknologia, rehun kuljetus ja säilytys, kuin rehuarvot.

Taulukko 6. Lanttu- ja porkkanamassoista tehdyt rehuanalyysit.

\begin{tabular}{|c|c|c|c|c|c|c|c|c|}
\hline & $\begin{array}{c}\text { Kuiva- } \\
\text { aine } \\
\text { (ka) \% }\end{array}$ & $\begin{array}{c}\text { Tuhka } \\
\text { g/kg } \\
\text { ka }\end{array}$ & $\begin{array}{c}\text { Raaka- } \\
\text { valkuainen } \\
\text { g/kg ka }\end{array}$ & $\begin{array}{c}\text { Raaka- } \\
\text { rasva } \\
\text { g/kg/ka }\end{array}$ & $\begin{array}{c}\text { Raaka- } \\
\text { kuitu } \\
\text { g/kg ka }\end{array}$ & $\begin{array}{c}\text { Typettömät } \\
\text { uuteaineet } \\
\text { g/kg ka }\end{array}$ & $\begin{array}{c}\text { Orgaanisen } \\
\text { aineen sula- } \\
\text { vuus g/kg }\end{array}$ & $\begin{array}{c}\text { RY } \\
\text { ry/kg } \\
\text { ka }\end{array}$ \\
\hline Lantunkuori & 8,84 & 88 & 163 & 16 & 153 & 580 & 921 & 1,04 \\
\hline Porkkanankuori & 10,1 & 118 & 50 & 20 & 97 & 716 & 893 & 1,07 \\
\hline
\end{tabular}

\section{Perunankuorimojätteen säilyvyyskokeet}

Kokeen aikana 0-käsittelyissä tapahtui 2-3 ensimmäisen päivän aikana käymistä, jolloin rehu turposi lieriössä. Hapen kanssa tekemisissä olleet massat lieriön yläosassa tummuivat 0-käsittelyssä noin $5 \mathrm{~cm}$ syvyyteen asti ja säilöntäainekäsittelyissä $1-2 \mathrm{~cm}$ syvyyteen asti. Tummuneessa pinnassa kasvoi hometta ja sen haju oli voihappomainen. Tummuneen pinnan alla rehu oli raikkaan hajuista kaikissa käsittelyissä.

AIV 2+ ja AIV 2000 lisäyksien jälkeen käyminen oli vähäisempää, mikä näkyy korkeina sokeripitoisuuksina ja pieninä maito- sekä etikkahappopitoisuuksina. Ilman säilörehulisäystä rehussa tapahtui luontaista maitohappokäymistä, jonka tuloksena sokeripitoisuus laski, maito- ja etikkahapon pitoisuudet nousivat. Haitallinen voihappokäyminen oli vähäistä, sillä voihapon määrät olivat alhaisia.

\section{Johtopäätökset}

Vihannesjäte on helposti kompostoituvaa, kunhan olosuhteet ovat oikeat. Kostea kuorimojäte vaatii runsaasti seosainetta, esim. turvetta ja haketta. Rumpukompostointi nopeuttaa vihannesjätteen kompostoitumista. Viikon rumpukompostoinnin jälkeen kompostoitu seos oli homogeenista, miltei hajutonta, höyryävää massaa, jota on helppo käsitellä. Rumpukompostoinnin jälkeen jäte vaatii vielä jälkikompostoinnin aumassa.

Tehokas tapa hyödyntää peruna- ja vihanneskuorimojätettä on sen käyttö eläinten rehuna. Peruna- ja vihannesmassa on hyvää ravintoa nautaeläimille muun rehun joukkoon sekoitettuna, jolloin $\mathrm{mm}$. rehun kuiva-aine- ja rasvapitoisuudet saadaan sopiviksi. Käytettäessä juuresmassaa sianrehuna, se on kuumennettava. Porkkana ja lanttu soveltuvat hyvin märehtijöiden rehuksi, joko kuorimassana tai kokonaisina ja niiden sulavuus on korkea. Porkkanan ja lantun käyttöä märehtijöiden rehuna rajoittavat rehun säilyvyys ja hygieeninen laatu sekä ruokintateknologia, kuljetus ja säilytys.

\section{Kirjallisuus}

Anderson, V. \& Schatz, B. 2003. Biological and economic synergies, and methods of integrating beef cow and field crops enterprises. In: 2002 Unified Beef Cattle and Range Research Report Agricultural Experiment Station, Department of Animal and Range Sciences, North Dakota State University. Saatavana internetistä: http://www.ext.nodak.edu/extpubs/ansci/beef/2002/beef01.htm\#biological, luettu 13.10.2005

Boyles, S. 2004. Feeding potato processing wastes and culls to cattle. Potato processing wastes and culls_OSU Extension Beef Team Library. Ohio State university Extension. Saatavana internetistä: http://beef.osu.edu/library/potato.html 14.6.2004.

Bradshaw, L., MacGregor, S \& Olsen, T. 2002. Potato by product feeding in the Pacific Northwest. Veterinary Clinics of North America Food Animal Practice 18 (2): 339-347.

Bruns, C., Gottschall, R., Marchiniszyn, E., Schüler, C., Zeller, W., Wolf, G., \& Vogtmann, H. 1994. Phyto-hygiene of composting-Present state and test methods in German. Proceedings of BMFT seminar on new techniques of composting. Hamburg. p. 191-206.

Hoitink, H. A. J. \& Poole, H. A. 1980. Bark compost use in container media. Compost Science 21: 3, 38-47. 
MMM 2004. Maatilatilastollinen vuosikirja 2004. Helsinki. 268 s.

MTT 2004. Rehutaulukot ja ruokintasuositukset. märehtijät - siat - siipikarja - turkiseläimet - hevoset. Maa- ja elintarviketalouden tutkimuskeskus. MTT:n selvityksiä 86, 85 s.

Murphy, S. 1997. Feeding potato by-products Prince Edward Island Agriculture and Forestry Factsheet AGDEX420-68. Saatavana internetistä: http://www.gov.pe.ca/photos/original/af fact_wast.pdf luettu 06.10.2005

Ruuttunen, P., MTT, 8.11.2004, henkilökohtainen tiedonanto.

Valaja, J., MTT, 22.6.2004, henkilökohtainen tiedonanto.

Virtanen, H. \& Salo, T. 2005. Kasvijäte puoliksi pellolle ja eläimille. Puutarha \& kauppa 17/2005: p. 8-9.

Wlcek,S. \& Zollitsch,W. 2004. Sustainable pig nutrition in organic farming: By-products from food processing as a feed resource. Renewable Agriculture and Food Systems, 19(3):159-167. 